\title{
Nutrition in Relation to Disease
}

$\mathrm{T}$ HE symposium on nutrition in relation to disease at the Aberdeen meeting of the British Association took the form of a joint meeting of Sections I (Physiology) and M (Agriculture). In the last ten years there has been a great development of research in the nutrition of farm animals. There are now two institutions-one at Cambridge and one at Aberdeen--devoted entirely to research in this subject. The meeting served the purpose of bringing together for review, results obtained in the medical field, where conclusions are drawn from experiments on small laboratory animals and from clinical observations on human beings, and those obtained in work with the larger domestic animals. Though the papers showed that the fundamental principles and the major problems are the same in both fields, they brought out the fact, sometimes overlooked, that the requirements for adequate nutrition and the effects of deficiencies of the various food constituents are not the same in all species. Dr. H. H. Green emphasised the necessity for caution in applying directly in medical or veterinary practice, results obtained with experimental animals.

The review showed that in the last twenty years, advance in knowledge has been so great that our ideas with regard to the etiology and treatment of many diseases have been revolutionised. It looks as if the science of nutrition may prove as important in the prevention of disease as the science of bacteriology.

In the case of certain deficiency diseases such as scurvy and rickets, the connexion between nutrition and disease is now established, and the dietary factor involved clearly defined. Investigators have moved on to the study of long-continued minor degrees of malnutrition which do not produce early gross signs of disease. To what extent do animals in this condition suffer from decreased resistance to bacterial or parasitic attack, and to what extent does this condition lead to the development of chronic diseases of digestion and metabolism ?

Dr. D. Robertson gave data to prove that in the case of coccidiosis in chickens and intestinal parasites in sheep, the state of nutrition of the animal is an important factor in determining both the extent and the effect of infestation. The results of these observations are now being applied successfully in practice. In the case of bacterial infection, carefully controlled experiments have shown that, with certain micro-organisms, animals in a poor state of nutrition show lowered resistance. In other cases, however, negative results have been obtained. This is a difficult field of inquiry, in which progress must be slow, as the nature and significance of immunological reactions are still obscure.

The bearing of nutrition on chronic diseases was discussed in each of the three leading papers (Dr. J. B. Orr, Prof. J. J. R. Macleod and Prof. S. J. Cowell). In the beginning of the present century, the influence of pathological conditions on metabolism was studied usually on the assumption that the abnormal metabolism was secondary to the pathological condition. The conception that disease may arise from a faulty diet has stimulated research from the point of view that the pathological condition is the result of the disordered metabolism, which may be present long before any clinical signs are evident. Data were given showing that in minor degrees of malnutrition the composition of fluids and tissues in the body is abnormal, and that these abnormalities give rise to dysfunction. It was suggested that the continued dysfunction might ultimately give rise to chronic disease. This condition is of special importance in early life. Deficiencies of certain substances in the food in the phase of active growth may lead to imperfect development of tissues, and so predispose to disease in later life. Dr. May Mellanby's paper on teeth illustrated the importance of perfect nutrition even in the pre-natal period.

In the present stage of very limited knowledge, the most that can be said is that the observations made are suggestive. Much patient and laborious investigation, however, is needed before we can speak with any degree of assurance on the relative importance of nutrition, heredity and environmental factors in the etiology of chronic diseases of metabolism. There is reason to believe, however, that this may be a fruitful line of inquiry. The study of some of these diseases from the nutritional point of view has already led to striking results. Ascorbic acid (vitamin C) seems to be effective in curing several diseases such as purpura hæmorrhagica, pyorrhœa and certain forms of hæmorrhagic nephritis. Progressive muscular atrophy seems to yield to treatment with an amino-acid, glycine. Psoriasis, in some cases at least, is cured by eliminating cholesterol and allied fatty substances from the diet. The treatment of pernicious anæmia with liver is now a well-established practice. These are diseases for which, until recently, medicine could provide no very satisfactory treatment. It may well be that these are merely the first fruits of the modern attack from the nutritional point of view on chronic diseases of obscure etiology.

The practical bearing of this recently acquired 
knowledge on the incidence of disease was discussed by several speakers, and the results of investigations on the connexion between faulty diet and disease in the community were quoted in support of the suggestion that disease due to faulty diet is prevalent. Thus, an investigation showed that about 50 per cent of women of the child-bearing age among the working classes in one of our cities were suffering from nutritional anæmia. The addition of milk to the diet of school children was followed by 20 per cent increase in rate of growth and by improvement in health. A large proportion of children are evidently not attaining their full inherited capacity for health. It was suggested that much of the disease in later life may be due to malnutrition in childhood and that this may have a bearing on the large number of rejections of recruits from the army, owing to poor physique or chronic disease.

If, indeed, disease due to faulty dietary should eventually prove to be as prevalent as these isolated and limited observations suggest, then there are obvious economic and political implications, especially at the present time, when we are moving towards a planned economic system under which the amount of certain foodstuffs coming on the market and the price at which they may be retailed, may be fixed for purely economic reasons. As a matter of fact, we have not sufficient data to warrant making an authoritative statement on the subject. Experimental observations have been far too limited in extent and too academic in nature to permit of wide generalisation. Sir Frederick Gowland Hopkins wisely counselled caution in the interpretation of the limited facts available. The urgent need of the present time is large-scale investigations over a number of years in different sections of the community in order to obtain data which may be applicable to the populace as a whole.

\section{Pit-Head Generation of Electric Power}

\section{(From a CoRrespondent)}

TN $\mathrm{N}$ his presidential address before the Engineering Section at the recent British Association meeting at Aberdeen on "Sources of Cheap Electric Power", Prof. F. G. Baily advocates the establishment of electric generating stations at the pitheads, his contention being that with low-grade coal and 'waste' fuel having a calorific value of 10,000 B.Th.U. per lb. available at a cost of five shillings per ton, electricity could be produced at one-twentieth of a penny per unit below the cost of production at the most modern steam stations now operating.

Prof. Baily very properly refers to the heavy burden of local rates on electricity undertakings, amounting in some cases to $0 \cdot 1 d$. per unit sold, and suggests that a substantial reduction may be claimed such as a half, amounting to $0.05 d$. per unit which, with the equal saving which the pithead station with cheap fuel can achieve, will bring about a reduction of $0 \cdot 1 d$. per unit. The present cost of generation at large stations he puts at $0 \cdot 25 d$. In this figure, $0 \cdot 25 d$. per unit generated, rates (on the generating station alone), as Prof. Baily says, may amount to $0.06 d$. per unit, and on the whole undertaking often as much as $0 \cdot 1 d$. per unit sold. This is a serious addition to the price which users of electricity have to pay. At least one undertaking selling many millions of units every year pays more in rates than it does for the coal required to generate all the electricity it sells. With the generating stations of industrial concerns de-rated, a substantial reduction in the rating of public utility stations appears to be a reasonable demand, but any reduction obtained would apply equally to the existing stations and to the proposed pit-head stations and would not affect a comparison between the two.

Prof. Baily visualises a pit-head station (perhaps many stations) having a daily output of about one million units. A saving of one-twentieth of a penny per unit would therefore be well worth striving for, and if such a saving could be effected it seems strange that nothing is being done to connect one such station to the Grid. It is only fair to say that such proposals are not new. In 1919 the Nitrogen Products Committee, with some of the most eminent engineers and other wellknown scientific men of the day among its members, referring to the subject, said :

"It has often been advocated that large power stations should be situated at the collieries or even at the pit's mouth in order that the cost of coal delivered into the bunkers may be reduced to the lowest possible point. This would be perfectly sound provided the other principal requirement of a cheaply operated power station could be obtained at the same site, namely, an abundant natural supply of circulating water for condensing purposes, capable of being utilised without undue cost of pumping. In the case, for example, of a station loaded to $100,000 \mathrm{k} . w$. at least six million gallons of condensing water would be required per hour on a load factor of $95 \%$-some $136,000,000$ gallons per day. The only alternative to a large supply of cooling water is to use cooling towers with a consequent large permanent loss of water by evaporation and a considerable increase in the temperature of the condensing water leading to a serious addition to the 